\title{
Prevalence of Low Back Pain and Associated Risk Factors Among Adama Hospital Medical College Staff, Ethiopia
}

\author{
Alem Deksisa Abebe ${ }^{1,}$, , Ephrem Mamo Gebrehiwot ${ }^{2}$, Seblewengel Lema ${ }^{3}$, Tilaye Workineh Abebe \\ ${ }^{1}$ Department of Public Health, Adama Hospital Medical College, Adama, Ethiopia \\ ${ }^{2}$ Department of Public Health, Faculty of Health Sciences, Assosa University, Assosa, Ethiopia \\ ${ }^{3}$ School of Public Health, Addis Continental Institute of Public Health, Addis Ababa, Ethiopia \\ ${ }^{4}$ Department of Public Health, Adama Hospital Medical College, Adama, Ethiopia
}

\section{Email address:}

alemdeks@yahoo.com (A. D. Abebe), ephremmamo@yahoo.com (E. M. Gebrehiwot), sebeye2007@gmail.com (S. Lema), tlife2002@gmail.com (T. W. Abeb)

\section{To cite this article:}

Alem Deksisa Abebe, Ephrem Mamo Gebrehiwot, Seblewengel Lema, Tilaye Workineh Abebe. Prevalence of Low Back Pain and Associated Risk Factors Among Adama Hospital Medical College Staff, Ethiopia. European Journal of Preventive Medicine. Vol. 3, No. 6, 2015, pp. 188-192. doi: 10.11648/j.ejpm.20150306.15

\begin{abstract}
Back ground: Low back pain (LBP) is one of the most common work-related health problems among hospital workers. Work-related activities such as twisting, bending, sustained posture, repeated movements are regarded as associated risk factors for low back pain. The aim of this study is to assess the prevalence and associated risk factors of Low Back Pain among hospital workers. Methodology: An institution based cross sectional survey design was conducted among employees in Adama Hospital Medical College (AHMC), Adama Ethiopia. Descriptive statistics, bivariate, and multiple regression analyses were performed. $\mathrm{p}<0.1$ in univariate is considered for multivariate analysis and $\mathrm{p}<0.05$ was used to define statistical significance. Result: Of 263, 137(52.1\%) were males and 126(47.9\%) were females. The result indicated that the mean and median age of the respondents were 33.5 and 33 years respectively. The life time prevalence of LBP was found to be $50.6 \%$ and the 12 month LBP prevalence was $41.4 \%$. Staff not participating in any physical activity (exercise) were more likely to report presence of low back pain (AOR (Adjusted Odd Ratio)=1.75, CI, 1.02-3.02). On the other hand, staff who worked sitting more than 6 hours were associated with increased risk of low back pain( $\mathrm{AOR}=2.78, \mathrm{CI}, 1.09-7.07)$. Perceived stress often increased risk of low back pain $(\mathrm{AOR}=2.60, \mathrm{CI}, 1.06-6.36)$. Conclusion: LBP was significantly associated with the obesity, stressed often, those worked in seated position more than six hours and those with long year experience; but doing physical exercise has rather a preventive effect. The findings of this study suggest that primary prevention of LBP should be considered.
\end{abstract}

Keywords: Low Back Pain, Prevalence, Associated Risk Factors, Hospital Staff

\section{Introduction}

\subsection{Back Ground}

Low back pain (LBP) is one of the most common musculoskeletal conditions in the general population. The burden of LBP is enormous in terms of quality of life, productivity, and employee absenteeism, making these common conditions the single largest contributor to musculoskeletal disability worldwide.LBP is defined as pain localized between the 12th rib and the inferior gluteal folds, with or without leg pain $(1,2)$.Diagnosis of LBP based on self-reported questionnaire has been used to estimate the prevalence of LBP in epidemiological study of community setting(3).Low back pain can be acute, subacute or chronic. It affects children to elderly and is a very common reason for medical consultations (4).

Prevalence of LBP varied depending on definitions and study populations and also differs from countries to countries. The point prevalence, or the percentage of people experiencing LBP at a given moment in time, was reported between $21.5 \%$ and 57\% (4-6). One-year prevalence or LBP event in the past 12 months was reported between 37.8 and $61.3 \%$ (7-9). The 6monthprevalence was reported between 40.8 and $42.6 \%(11,12)$, and the lifetime prevalence was reported between 61.6 and $70 \%(5,8)$.As part of the Global Burden of 
Disease Study (GBD), the Expert Group showed that low back pain is among the top ten high burden diseases and injuries, with an average number disability-adjusted life years (DALYs) higher than HIV, road injuries, tuberculosis, lung cancer, chronic obstructive pulmonary disease and preterm birth complications Until recently it was largely thought of as a problem confined to western countries but research performed during the last decade clearly showed that low back pain is also a major problem in low- and middle-income countries(5).

Low back pain can be due to a number of factors including: individual characteristics, working conditions such as heavy physical work, ward static and dynamic working postures, as well as manual handling and lifting, lifestyle factors and psychological factors. A minority of cases of low back pain results from trauma to the back, osteoporosis or prolonged corticosteroid use. Relatively less common are vertebral infections, tumors and bone metastasis (4, 5, and 7).

Little has been done on the relationship of low back pain and associated risk factors on a population of hospital employees in Ethiopia, specifically Adama. The aim of this study is to investigate the prevalence and associated risk factors of low back pain among staff employed at AHMC, in central Ethiopia.

LBP has been studied most frequently amongst nurses, nursing aides and other direct caregivers $(9,10)$, but despite the high reported prevalence of LBP among hospital staff in these studies, there is no information available on the comparative prevalence of LBP among hospital workers in Adama. Specific information on associated risk factors and LBP in different professional groups is needed for preventive interventions to aim at reducing musculoskeletal complaints to be better targeted.

\section{Methods}

\subsection{Study Design and Setting}

A institution based cross- sectional study design was conducted in AHMC, Shoa Zone, Oromia Regional State, Ethiopia. AHMC is one of the first hospitals medical college situated in Adama town, and was inaugurated by missionaries from abroad in 1946 G.C.

The data collection was conducted from December, 2014 to January, 2015. Sampling with simple random sampling method was used to get the required sample size. Numbered lists of all the population of Adama Hospital Medical College staff were made and 300 study subjects were randomly selected using lottery method from the 460 (278 professional and 182 supporting staff).

Data collection was carried out using an interviewer administered pre-tested, structured, and standardized questionnaire. The questionnaire was initially prepared in English and then was translated in to Amharic (the local language) and later on back to English to check for consistency. Participants were interviewed by trained interviewers. Supervisors followed the data collectors and provided any necessary correction on the spot.

Ethical approval of the study was obtained from Addis continental Institute of Public Health (ACIPH) and Adama science and Technology University (ASTU) ethical review board. The participants were informed about the purpose of the study and oral consent was obtained from each study participants prior to conducting the interview.

\subsection{Sample Size Determination}

A sample size calculation was performed using the STATCALC program of EPINFO V.7 to estimate the two population proportion of male and female gender with LBP. The following assumptions were made to obtain the maximum sample size P1=percentage of LBP among female sex was $64 \%$; $22=$ percentage of LBP among male sex was $36 \%$ (27).A two sided significance level of $0.05,95 \% \mathrm{CI}$ and power of $80 \%$ were used. The female to male ratio was $1: 1$. Based on this sample size calculation, including $10 \%$ nonresponse rate the total sample is 300 .

\subsection{Statistical Analyses}

Data were entered into EPI INFO (Version 3.5.4), and exported to SPSS (Version 20.0) for statistical analysis. We first explored frequency distributions of socio demographical and Descriptive statistics was used to summarize and present the information in the form of percentages and tables with $95 \%$ confidence intervals for prevalence estimates. Binary logistic regression analysis was used to examine the association between LBP and risk. Both crude and adjusted odds ratio are presented with a $95 \%$ confidence interval. $\mathrm{p}<0.1$ in univariate is considered for multivariate analysis and $\mathrm{p}<0.05$ was used to define statistical significance.

Dependent variable

LBP (Low Back Pain)-any pain, ache, or discomfort, felt below the costal margin and above the inferior gluteal folds, with or without leg pain for at least one day duration.

Independent variable

Exercise: a subset of physical activity that is designed, controlled, and repetitive and has as an ultimate or an intermediate objective.

Stress-perceived mental, emotional, or physical strain caused by anxiety or overwork.

BMI (Body Mass Index) - the weight in kilograms, divided by height in meters squared

Heavy manual labor- defined as work that has high energy demands or requires some measure of physical strength and jobs that impose large compressive forces on the spine.

Manual materials and patient handling- Manual materials handling include lifting, moving, carrying and holding loads during working time. The concept encompasses stresses resulting from work done in transferring objects from one place to another as well as the effects of varying techniques of patient handling and transfer. 


\section{Results}

The respondents back grounds are summarized in table 1. A total of three hundred Adama Hospital Medical College staffs were invited to participate in the survey and the response rate was $90.7 \%$, but $9(3 \%)$ of the responses were excluded from the analysis because of their incomplete responses; while 263 fully participated in the study. The males staff were $(n=137,52.1 \%)$ and the females staff were $(\mathrm{n}=126,47.9 \%)$. The participants' ages ranged from 19 to 52 years, with mean age of 33.5 years $(\mathrm{SD}=6.7)$.

The majority of the respondents $163(62 \%)$ were married. $85(32.3 \%)$ had working experience of above 12 years, followed by $69(26.2 \%)$ having work experience of between 1 and 4 years. The predominant age group 164(62.4\%) was the age group between 26 and 40.Among all the respondents $83(31.6 \%)$ were Nurses and $77(29.3 \%)$ were Admin staffs.

Table 1. Socio-demographic characteristics of Adama Hospital Medical College staff, Ethiopia, 2015.

\begin{tabular}{|c|c|c|}
\hline Variables & Frequency & Percentage (\%) \\
\hline \multicolumn{3}{|l|}{ Age category } \\
\hline$<25$ & 38 & 14.4 \\
\hline $26-40$ & 164 & 62.4 \\
\hline $41-60$ & 61 & 23.2 \\
\hline \multicolumn{3}{|l|}{ Sex } \\
\hline male & 137 & 52.1 \\
\hline female & 126 & 47.9 \\
\hline \multicolumn{3}{|l|}{ Marital status } \\
\hline single & 86 & 32.7 \\
\hline married & 163 & 62.0 \\
\hline divorced & 10 & 3.8 \\
\hline widowed & 4 & 1.5 \\
\hline \multicolumn{3}{|l|}{ Work experience } \\
\hline $1-4$ & 69 & 26.2 \\
\hline $5-8$ & 63 & 24.0 \\
\hline $9-12$ & 46 & 17.5 \\
\hline$>12$ & 85 & 32.3 \\
\hline \multicolumn{3}{|l|}{ Occupation } \\
\hline admin staff & 77 & 29.3 \\
\hline doctor & 36 & 13.7 \\
\hline nurse & 83 & 31.6 \\
\hline technicians/technologists & 25 & 9.5 \\
\hline druggists/pharmacists & 13 & 4.9 \\
\hline other(specify) & 29 & 11 \\
\hline \multicolumn{3}{|l|}{ body mass index category } \\
\hline$<25$ & 198 & 75.3 \\
\hline$\geq 25$ & 65 & 24.7 \\
\hline
\end{tabular}

Socio-demographic, individual and work factors that showed significant associations with presence of low back pain in Univariate analysis were selected and entered for Multivariate logistic regression analysis to identify the most important predictors of low back pain risk factors. Accordingly, staff who worked greater than 12 years report presence of low back pain than that of working less than or equal to 12 years, Crude Odd ratio $(\mathrm{COR})=1.95,95 \% \mathrm{CI}$, 1.02-3.73), staff with BMI greater than or equal to 25 kilogram per meter square report presence of low back pain than staff with BMI less than 25 kilogram per meter square $(\mathrm{AOR}=2.08,95 \% \mathrm{CI}, 1.07-4.05)$ and also staff who didn't participate in any physical exercise report presence of low back pain than who did participate $(\mathrm{AOR}=1.75,95 \% \mathrm{CI}$, 1.02-3.02). But age category, sex, marital status, walking, running and group exercise were found to have no association with low back pain. The factor, working experience, was found to have no association with low back pain after controlling other factors. On the other hand, staffs who worked sitting more than 6 hours were 2.78 times more likely to have odds of low back pain than those working between 0-1 hours. Similarly, staffs that faced stresses often were, 2.60 times more likely to have odds of low back pain than those staff facing no stress.

Table 2. Life style and work conditions of Adama Hospital Medical College staff, Ethiopia, 2015.

\begin{tabular}{|c|c|c|}
\hline Variables & Frequency & Percentage (\%) \\
\hline \multicolumn{3}{|l|}{ Alcohol } \\
\hline no & 205 & 77.9 \\
\hline yes & 58 & 22.1 \\
\hline \multicolumn{3}{|l|}{ Smoking } \\
\hline No & 252 & 95.8 \\
\hline Yes & 11 & 4.2 \\
\hline \multicolumn{3}{|c|}{ How often do you do exercise } \\
\hline $0-2$ times per week & 166 & 63.1 \\
\hline 3-4 times per week & 61 & 23.2 \\
\hline 5-7 times per week & 14 & 5.3 \\
\hline$>7$ times per week & 22 & 8.4 \\
\hline Physical activity Exercise & 144 & 54.8 \\
\hline No exercise & 119 & 45.2 \\
\hline \multicolumn{3}{|l|}{ Lifting objects/people } \\
\hline no & 127 & 48.3 \\
\hline yes & 136 & 51.7 \\
\hline \multicolumn{3}{|l|}{ Stress at work } \\
\hline never & 53 & 20.2 \\
\hline sometimes & 169 & 64.3 \\
\hline often & 41 & 15.5 \\
\hline \multicolumn{3}{|l|}{ Hours spent sitting daily } \\
\hline $0-1$ & 90 & 34.2 \\
\hline $2-4$ & 86 & 32.7 \\
\hline $5-6$ & 57 & 21.7 \\
\hline$>6$ & 30 & 11.4 \\
\hline \multicolumn{3}{|l|}{ Hours spent standing daily } \\
\hline $0-1$ & 88 & 33.5 \\
\hline $2-4$ & 99 & 37.6 \\
\hline $5-6$ & 44 & 16.7 \\
\hline$>6$ & 32 & 12.2 \\
\hline
\end{tabular}

Predicting factors of low back pain

\section{Discussions}

Prevalence of low back pain varied depending on definitions and study populations and also from countries to countries. The point prevalence of low back pain in this study was, $28.9 \%$. This is similar to study done in different countries of Africa with point prevalence of low back pain which varies between $16 \%$ and $59 \%(14,15)$; as well as study done in European countries with point prevalence of between $21.5 \%$ and $57 \%$ (4-6). However, it is much lower than point prevalence rates of $35.8 \%$, reported in South Africa (12). But it is higher than in $\mathrm{UK}$, the point prevalence is $19 \%(12,13)$. 
The 12 month prevalence of low back pain among participants in this study was $41.4 \%$ and the overall life time prevalence was $50.6 \%$. The one year prevalence was in the range of $14 \%$ to $72 \%$ and the life time prevalence was in between $28 \%$ and $74 \%$ as reported by African countries (14, 15). The one year prevalence was also in the annual prevalence reported in industrialized countries, varying between $15 \%-45 \%$ (4). However, it is lower than annual prevalence of $51 \%$ and life time prevalence of $57.7 \%$ in Tunisia (9); as well as annual prevalence of $56.9 \%$ and life time prevalence of $72.5 \%$ in Malaysia (21). But the life time prevalence is comparable with life time prevalence of $51 \%$ in Turkey (20).

Variability in low back pain prevalence may be explained by the methodological heterogeneity used for assessment of low back pain as well as by differences in the gender, profession and age group of the other study populations (4, 7).

Work experience of the respondents was associated with low back pain; for those with years of service greater or equal to twelve years $(p=0.035)$. A similar link has been found in Tunisia $(\mathrm{p}=0.007)$ (9). Similar findings were also obtained from Gondar (AOR: 2.4; 95\%CI $(1.41,4.19)$ ). In an Italian study of hospital nurses, work experience was significantly associated with low back pain (11). However, other studies have found no such associations $(16,18-20)$. It is agreed that the prevalence of low back pain increases as people enter their working years (7).

Table 3. Correlates of Low back pain among Adama Hospital Medical College staff, Ethiopia, 2015.

\begin{tabular}{|c|c|c|c|c|c|c|}
\hline \multirow{2}{*}{ Variables } & & \multicolumn{2}{|c|}{ Low Back Pain } & \multicolumn{3}{|l|}{ OR(95\%)CI } \\
\hline & & Yes & No & Crude & Adjusted & p-value \\
\hline \multirow{3}{*}{ Age } & $<25$ & 14 & 24 & 1.00 & 1.00 & 0.072 \\
\hline & $26-40$ & 62 & 102 & $1.04(0.50-2.16)$ & $0.93(0.38-2.32)$ & \\
\hline & $41-60$ & 33 & 28 & $2.02(0.88-4.63)$ & $1.00(0.28-3.57)$ & \\
\hline \multirow{2}{*}{ Sex } & Male & 49 & 88 & 1.00 & 1.00 & \\
\hline & Female & 60 & 66 & $1.63(0.99-2.68)$ & $1.40(0.81-2.42)$ & \\
\hline \multirow{3}{*}{ Work experience } & $5-8$ & 21 & 42 & $0.83(0.40-1.69)$ & $1.01(0.44-2.31)$ & \\
\hline & $9-12$ & 16 & 30 & $0.88(0.41-1.92)$ & $0.91(0.35-2.33)$ & \\
\hline & $>12$ & 46 & 39 & $1.95(1.02-3.73)$ & $1.28(0.48-3.43)$ & \\
\hline BMI & $<25$ & 72 & 126 & 1.00 & 1.00 & 0.004 \\
\hline Cat. & $\geq 25$ & 37 & 28 & $2.31(1.31-4.09)$ & $2.08(1.07-4.05)$ & \\
\hline No Exercise & Yes & 61 & 58 & $2.1(1.28-3.47)$ & $1.75(1.02-3.02)$ & \\
\hline \multirow{4}{*}{$\begin{array}{l}\text { Time spent during } \\
\text { an } 8 \text { hour working } \\
\text { day by sitting }\end{array}$} & $0-1 \mathrm{hrs}$ & 37 & 53 & 1.00 & 1.00 & 0.007 \\
\hline & $2-4 \mathrm{hrs}$ & 30 & 56 & $0.77(0.42-1.41)$ & $0.70(0.36-1.35)$ & \\
\hline & $5-6 \mathrm{hrs}$ & 21 & 36 & $0.84(0.42-1.63)$ & $0.83(0.40-1.72)$ & \\
\hline & $>6 \mathrm{hrs}$ & 21 & 9 & $3.34(1.38-8.10)$ & $2.78(1.09-7.07)$ & \\
\hline \multirow{3}{*}{ Stress } & Never & 20 & 33 & & & 0.012 \\
\hline & Sometimes & 63 & 106 & $0.98(0.52-1.85)$ & $1.04(0.53-2.05)$ & \\
\hline & Often & 26 & 15 & $2.86(1.23-6.65)$ & $2.60(1.06-6.36)$ & \\
\hline
\end{tabular}

According to this study, body mass index was found to be associated with low back pain $(\mathrm{AOR}=2.08$ : 95\%CI (1.07, 4.05)). This is in accordance with study done in Gondar $(\mathrm{AOR}=3.52$ : $95 \% \mathrm{CI}(1.02,12.04))(13)$. Similar findings were also reported by a meta-analysis including 33 studies showed that obesity was associated with increased prevalence of low back pain in the past 12 months (pooled OR=1.33 (95\%CI: 1.14-1.54) (8). Conversely, a study of Italian hospital workers didn't show any body mass index difference between workers with or without low back pain (11).

According to this study exercise was associated with low back pain $(\mathrm{p}=0.04)$. Participating in any physical exercise reduces the prevalence of low back pain compared to not participating in any physical exercise. In the same way studies done in India showed significant association between physical activities (exercise) and prevalence of low back pain (19).

Static work postures include positions where very little movement occurs, along with cramped or inactive postures that cause static loading on the muscles. In many cases, the exposure defined subjectively and/or in combination with other work-related risk factors $(4,12)$. The result of this study suggests that working in position seated for a long duration was positively associated with low back pain. Similar findings have been demonstrated by study done in Tunisia (9).

On the other hand, result of this study suggests that stress at work was found to be a low back pain associated risk factor $(\mathrm{p}=0.012)$, in accordance to the literature $(4,8,19,20)$. These literatures included a wide range of psycho-social factors; which is not included in this study.

\section{Conclusion}

This study indicates that low back pain was a common health problem among the AHMC staffs studied. It was more prevalent in the middle age brackets and among females. LBP was significantly associated with the obese, stressed often, those worked in seated position more than six hours 
and those with long year experience; but doing physical exercise has rather a preventive effect. The findings of this study suggest that primary prevention of LBP should be considered. The common prevalence of LBP requires multidisciplinary involvement in order to reduce the morbidity and associated risk factors.

\section{Author's Contributions}

$\mathrm{AD}, \mathrm{EM}$ and SL were involved in the design and conception of the study; the analysis and interpretation of the findings. $\mathrm{EM}, \mathrm{AD}$ and $\mathrm{TW}$ : involved in analysis, interpretation and writes up of the manuscript. All the authors read and approved the final content of the manuscript.

\section{Acknowledgements}

The Authors gratefully acknowledge all the participants and data collectors. The authors acknowledge AHMC department chairs for their general support.

\section{References}

[1] Krismer M, van Tulder M. Strategies for prevention and management of musculoskeletal conditions, Low back pain (non-specific). Best Pract Res Clin Rheumatol 2007; 21: 7791.

[2] Vuori IM. Dose-response of physical activity and low back pain, osteoarthritis, and osteoporosis. Med Sci Sports Exerc 2001; 33(6 Suppl): S551-86; discussion 609-10.

[3] Dionne CE, Dunn KM, Croft PR, Nachemson AL, Buchbinder $\mathrm{R}$, Walker BF, et al. A consensus approach toward the standardization of back pain definitions for use in prevalence studies. Spine (Phila Pa 1976) 2008; 33: 95-103.

[4] Béatrice D. Priority Medicines for Europe and the World "A Public Health Approach to Innovation" Update on 2004 Background Paper, BP 6.24 Low back pain 2013; 6.24-24.

[5] AlMazroa, Mohammad A. Years lived with disability (YLDs) for 1160 sequelae of 289 diseases and injuries 1990-2010: a systematic analysis for the Global Burden of Disease Study 2010. Lancet. 2012 Dec 15; 380(9859):2163-96. doi: 10.1016/S0140-6736(12)61729-2. Erratum in: Lancet. 2013 Feb 23; 381(9867):628.

[6] KARAHAN A., KAV S., ABBASOGLU A. \& DOGAN N. Low back pain: Prevalence and associated risk factors among hospital staff. Journal of Advanced Nursing 2009; 65(3), 5165242 .

[7] Lic. Rik Op De Beeck, Dr. Veerle Hermans Andersson workrelated low back disorders Luxembourg: Office for Official Publications of the European Communities, 2000 ISBN $92-$ 95007-02-6.
[8] European Guidelines for the Management of chronic non specific low back pain 2004. Website http://www.backpaineurope.org/web/files/WG2_Guidelines.p df.

[9] Bejia I., Younes M., Jamila H.B., Khalfallah T., Salem K.B., Touzi M., Akrout M. \& Bergaoui N. Prevalence and factors associated to low back pain among hospital staff. Joint Bone Spine 2005; 72(3), 254-259.

[10] Bos E., Krol B., van der Star L. \& Groothoff J. Risk factors and musculoskeletal complaints in non-specialized nurses, IC nurses, operation room nurses, and X-ray technologists. International Archives of Occupational and Environmental Health 2007; 80(3), 198-206.

[11] Lorusso A., Bruno S. \& L'abbate N. A review of low back pain and musculoskeletal disorders among Italian nursing personnel. Industrial Health 2007; 45(5), 637-644.

[12] Benita Naude Factors Associated with Low Back Pain in Hospital Employees. Johannesburg, 2008.

[13] Van Vuuren BJ, Becker PJ, Van Heerden HJ, Zinzen E \& Meunisen $\mathrm{R}$ Lower back problems and occupational risk factors in a South African steel industry, American Journal of Industrial Medicine 2005, 47 (5); 451-457.

[14] Louw QA, Morris LD and Grimmer-Somers K The prevalence of low back pain in Africa: a systematic review, BMC Musculoskeletal Disorders 2007, 9 (1): 105.

[15] Omokhodion F. O., Umar U. S. and Ogunnowo B. E. Prevalence of low back pain among staff in a rural hospital in Nigeria Occup. Med. 2000, Vol. 50, No. 2, pp. 107-110.

[16] Santhanee K., Paskorn S., Yongyuth S., Roongtiwa V. Prevalence and Risk Factors of Low Back Pain among the University Staff. J Med Assoc Thai 2010; 93 (Suppl. 7): S142S148.

[17] Patience N, Erick and Derek R Smith. Low back pain among school teachers in Botswana, prevalence and risk factors. BMC musculo-skeletal disorders 2014, 15: 359.

[18] Ahmed M.S, Basem M.M and Ahmed R. Association of low back pain with vitamin $\mathrm{D}$ deficiency and other common risk factors: A hospital based case-control study. European journal of preventive medicine 2015; 3(1): 1-5.

[19] Salvi Shah and Beena Dave. Prevalence of low back pain and its associated risk factors among Doctors in Surat. International Journal of health sciences and research. March 28, 2012 ISSN: 2249-9571.

[20] Altinel L. et al., The prevalence of low back pain and risk factors among adult population in Afyon region, Turkey. Acta Orthop Traumatol Turc 2008; 42(5): 328-333.

[21] Wong TS, Teo N and Kyaw MO. Pevalence and risk factors associated with low back pain Among Health Care Providers in a District Hospital Malaysian Orthopeadic Journal 2010 Vol 4 No 2. 